\title{
LIBERAÇÃO DE FERRO (III) DE MICROESFERAS RETICULADAS DE QUITOSANA
}

\section{RELEASE OF IRON (III) FROM CROSSLINKED CHITOSAN MICROSPHERES}

\author{
GONÇALVES, Vanessa Lima ${ }^{1}$; LARANJEIRA, Mauro C. M. ${ }^{1 *}$; FÁVERE, Valfredo ${ }^{1}$, DRAGO, \\ Valderes $^{2}$ \\ RECEBIDO: MAIO/2005 ACEITO: JUNHO/2005 \\ ${ }^{1}$ Departamento de Química UFSC \\ ${ }^{2}$ Departamento de Física UFSC \\ *autor para correspondência: mauro@qmc.ufsc.br
}

\begin{abstract}
Resumo:
Neste trabalho microesferas de quitosana reticuladas foram preparadas pelo método de coacervação simples e reticuladas com glutaraldeído e epicloridrina. Os efeitos dos agentes reticulantes nas microesferas foram testados com respeito ao grau de intumescimento, hidrólise, porosidade, reticulação, impregnação do ferro e conseqüente liberação em solução tampão $\mathrm{pH}$ 1,2, simulando o trato gastrointestinal. Análises de espectroscopia Mössbauer, infravermelho, análise termogravimétrica e microscopia eletrônica de varredura foram realizadas para avaliação das estruturas formadas.
\end{abstract}

Palavras chaves: biopolímeros, quitosana, complexos de Fe(III), anemia

\begin{abstract}
:
In this work chitosan microspheres were prepared by the simple coacervation method and crosslinked with epichlorhydrin and glutaraldehyde. The effects of the crosslinking agents on chitosan microspheres were assessed with regard to swelling, hydrolysis, porosity, crosslinking, impregnation of iron (III) and consequently release of iron in buffer solution $\mathrm{pH} 1.2$, simulating the gastrointestinal tract. The crosslinked chitosan microspheres containing iron were characterized by spectroscopy Mössbauer, infrared, thermogravometric analysis and scanning electron microscopy.
\end{abstract}

Keywords: biopolymer, chitosan, iron (III) complexes, anemia

\section{Introdução}

Nos últimos anos, o interesse pela classe de polímeros naturais conhecidos como polissacarídeos tem crescido consideravelmente, devido a sua abundância e aplicação biotecnológica e biomédica (BERGER et al., 2004). Os polissacarídeos são capazes de prevenir a precipitação de metais e manter grande quantidades de ferro (III) em soluções aquosas mesmo em condições fisiológicas. Esta capacidade de ligação ao ferro (III) tem levado a formação de compostos como dextrana ferro (III), sulfato de condroitina ferro (III), alginato ferro (III) usados como medicamentos no tratamento da anemia por deficiência de ferro (SIPOS et al.,1995; GEETHA et al., 1995; GYURESIK \& NAGY, 2000).

Aquitosana, $\beta$ - $(1 \rightarrow 4) 2$ amino 2-desoxi- D-glicose é um derivado desacetilado da quitina, um polímero encontrado em carapaças de crustáceos, cutículas de insetos e parede celular de alguns fungos. A quitosana apresenta vantagens sobre outros polissacarídeos devido a sua não toxicidade e biodegrabilidade. Por estas propriedades a quitosana tem sido usada como matriz de micropartículas e sistemas reticulados para imobilização e liberação de fármacos (HEJAZI \& AMIJI, 2003; GONÇALVES et al., 2005). Tanto os monos como polissacarídeos são conhecidos por formarem complexos estáveis com metais de transição. A quitosana é capaz de coletar 
seletivamente metais de transição através de ligações de troca iônica, sorção e quelação (OKUYAMA et al., 2000, JUSTI et al., 2004). A maneira como a quitosana interage com o ferro (III) ainda não é bem conhecida. Alguns autores sugerem a ligação

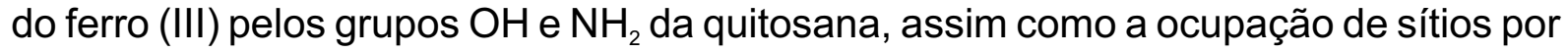
moléculas de água (NIETO; PENICHE-COVAS; DEL BOSQUE, 1992; BHATIA \& RAVI, 2000) Em contrapartida outros autores estabelecem pequena importância de grupos $\mathrm{NH}_{2}$ para a ligação com o ferro e sugerem a formação de núcleos férricos nestes compostos (GAMBLIN; STEVENS; WILSON, 1998; SIPOS et al., 2003).

Neste trabalho, a impregnação de ferro (III) nas microesferas reticuladas com epicloridrina e glutaraldeído foi investigada em relação a liberação do íon ferro (III) em solução de $\mathrm{pH} 1,2$, simulando o suco gástrico.

\section{Material e Método}

\subsection{Preparação das microesferas reticuladas e impregnadas com ferro (III)}

A solução quitosana $4 \%(\mathrm{p} / \mathrm{v})$ em ácido acético $5 \%(\mathrm{v} / \mathrm{v})$ foi gotejada com o auxílio de uma bomba peristáltica de marca Ismatec em um banho de precipitação contendo solução $\mathrm{NaOH} 2 \mathrm{~mol} / \mathrm{L}$ ocorrendo a formação das microesferas. Após trinta minutos nesta solução as microesferas foram lavadas até $\mathrm{pH}$ neutro e reticuladas.

Para a reticulação com epicloridrina $10 \mathrm{~g}$ de microesferas úmidas foram colocadas em $100 \mathrm{~mL}$ de água e adicionado $4,9 \mathrm{~mL}$ de epicloridrina e aquecido por 1 hora. Em seguida, foi adicionado $70 \mathrm{~mL}$ de $\mathrm{NaOH} 0,1 \mathrm{~mol} / \mathrm{L}$ e fervido por 2 horas. As microesferas foram lavadas com água, ácido clorídrico $0,1 \mathrm{~mol} / \mathrm{L}$ seguido de $\mathrm{NaOH} 0,1 \mathrm{~mol} / \mathrm{L}$ (1A).

Na reticulação com glutaraldeído utilizou-se a proporção de $1 \mathrm{~g}$ de microesferas úmidas para 1,5 mL de solução de glutaraldeído 2,5\% (v/v), permanecendo em contato por 24 horas. (2A). As microesferas reticuladas foram colocadas em uma solução saturada de $\mathrm{FeSO}_{4} .7 \mathrm{H}_{2} \mathrm{O}$ (solução de impregnação), permanecendo por 24 horas, sob agitação, sendo que após este período todo ferro (II) impregnado é convertido a ferro (III), na presença de ar atmosférico.

2.2 Determinação do grau de reticulação (GR) antes da impregnação com ferro

O grau de reticulação foi realizado pesando-se $1 \mathrm{~g}$ de microesferas não reticuladas úmidas e $1 \mathrm{~g}$ de microesferas reticuladas úmidas. Estas, a seguir, foram secas em estufa ${ }^{\circ} 50^{\circ} \mathrm{C}$ e pesadas novamente. O grau de reticulação foi calculado pela Equação 1

$$
G R=\left(m_{2}-m_{1}\right) / m_{1} \times 100
$$

onde $m_{2}$ e $m_{1}$ correspondem às massas das microesferas reticuladas secas e das microesferas não reticuladas secas, respectivamente. 


\subsection{Microscopia eletrônica de varredura (MEV) dos complexos de ferro (III)}

As fotomicrografias das microesferas foram obtidas empregando um microscópico eletrônico de varredura (SEM, Philips XL 30) para observação da morfologia e determinar o tamanho médio das microesferas. Para a realização das fotomicrografias, as micropartículas inteiras foram revestidas por uma camada de ouro. As microesferas $1 \mathrm{~A}$ e $2 \mathrm{~A}$ formadas são estruturas monolíticas esféricas e apresentam tamanho médio, calculado a partir da média de três micrografias contendo cada uma aproximadamente $20-25$ microesferas.

\subsection{Determinação do Grau de Intumescimento (GI)}

A determinação do grau de intumescimento foi realizada em soluções tampão $\mathrm{pH} 1,2, \mathrm{pH} 6,8$ e pH 9,0. Inicialmente as microesferas foram secas em estufa, pesadas (100 mg) e mantidas nas soluções tampão de $\mathrm{pH}$, a $37^{\circ} \mathrm{C}$. A cada 10 minutos foram retiradas, secas em papel filtro e pesadas novamente. O grau de intumescimento de cada amostra no tempo t foi calculado pela Equação 2

$$
G I=\left(m_{t} m_{o}\right) / m_{\circ}
$$

onde $m_{t}$ e $m_{o}$ são as amostras pesadas no tempo t e no estado seco, respectivamente.

\subsection{Determinação da concentração de ferro (III) nas microesferas}

As microesferas foram trituradas e em seguida colocadas em ácido nítrico 0,1 $\mathrm{mol} / \mathrm{L}$ sob agitação e aquecimento. O Fe(III) foi reduzido com hidroxilamina a $\mathrm{Fe}$ (II) e complexado com a 1,10 - fenantrolina ("fen") para a formação do complexo $\left[\mathrm{Fe}(\mathrm{fen})_{3}\right]^{2+}$ de estequiometria ${ }^{1}: 3$. O complexo absorve fortemente na região do visível $\left(\lambda_{\max }=510 \mathrm{~nm}\right)$ e a concentração foi determinada através da curva de calibração previamente realizada com sulfato ferroso.

\subsection{Estudo de Liberação in vitro}

Para se determinar a quantidade de fármaco liberado pelas microesferas de quitosana reticulada amostras de microesferas foram colocadas em um banho termostatizado a $37^{\circ} \mathrm{C}$, com agitação horizontal em $100 \mathrm{rpm}$, contendo $50 \mathrm{~mL}$ de solução tampão $(\mathrm{pH} 1,2)$ simulando o fluído gástrico do sistema trato gastrintestinal (TGI). As microesferas permaneceram em $\mathrm{pH} 1,2$ e alíquotas de $1 \mathrm{~mL}$ foram retiradas a cada 10 minutos totalizando 2 horas neste $\mathrm{pH}$ sendo o volume reposto. A concentração de ferro em cada amostra foi então quantificada por espectroscopia UV vis ( $\left._{\max }=510 \mathrm{~nm}\right)$ mediante curva de calibração.

A percentagem cumulativa do fármaco liberado foi calculada e a média de três determinações foi usada na análise dos dados. 


\section{Resultados e discussão}

As microesferas de quitosana foram preparadas pelo método de separação de fases, via coacervação simples. Segundo este método, a formação das microesferas resulta de um fenômeno de superfície e ocorre devido a interação entre a solução polimérica (solução de quitosana) e um meio coagulante (solução de $\mathrm{NaOH} 2 \mathrm{~mol} / \mathrm{L}$ ) o qual induz a separação de fases, precipitando a membrana polimérica.

As microesferas obtidas foram submetidas a dois processos de reticulação: com epicloridrina, denominada $1 \mathrm{~A}$ e com glutaraldeído denominada $2 \mathrm{~A}$. Em ambos os casos, a reticulação foi realizada com a finalidade de aumentar a resistência mecânica das microesferas e torná-las insolúveis em soluções ácidas.

Os agentes reticulantes usados ligam-se em diferentes grupos da quitosana. Os grupos aldeídos do glutaraldeído formam iminas com os grupos amino da quitosana devido a ressonância estabelecida com ligações etilênicas adjacentes via reação de base de Schiff (Figura 1) enquanto que a epicloridrina liga-se através dos átomos de carbono, resultantes da ruptura do anel epóxi e da remoção do cloro, com os grupos hidroxila do carbono 6 da quitosana (Figura 2) (GONÇALVES et al., 2005).

Após o processo de reticulação com epicloridrina (1A) ou glutaraldeído (2A) o grau de reticulação foi determinado, obtendo-se valores de $27 \%$ e $63 \%$ para as microesferas $1 \mathrm{~A}$ e 2A, respectivamente.

A superfície e morfologia externa e interna das microesferas de QTS Fe (III) reticuladas com glutaraldeído (2A) estão apresentadas na Figura 3 e das microesferas de QTS Fe (III) reticuladas com epicloridrina (1A) estão apresentadas na Figura 4 .

As microesferas $1 \mathrm{~A}$ e $2 \mathrm{~A}$ formadas são estruturas monolíticas esféricas e apresentam tamanho médio, calculado a partir da média de três micrografias contendo cada uma aproximadamente $20-25$ microesferas, de $0,790 \mathrm{~mm}$ e $1,344 \mathrm{~mm}$, respectivamente

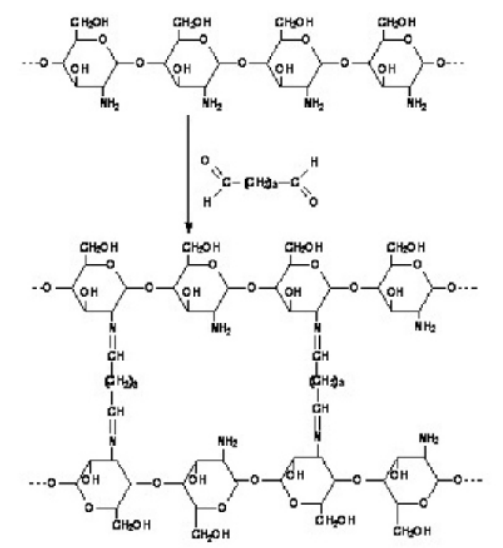

Figura 1. Processo de reticulação da quitosana tratada com glutaraldeído.

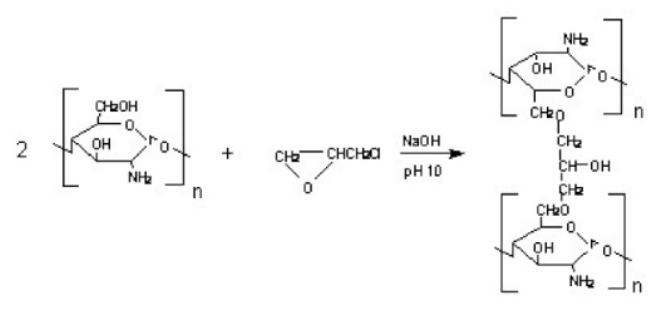

Figura 2. Processo de reticulação da quitosana tratada com epicloridrina. 


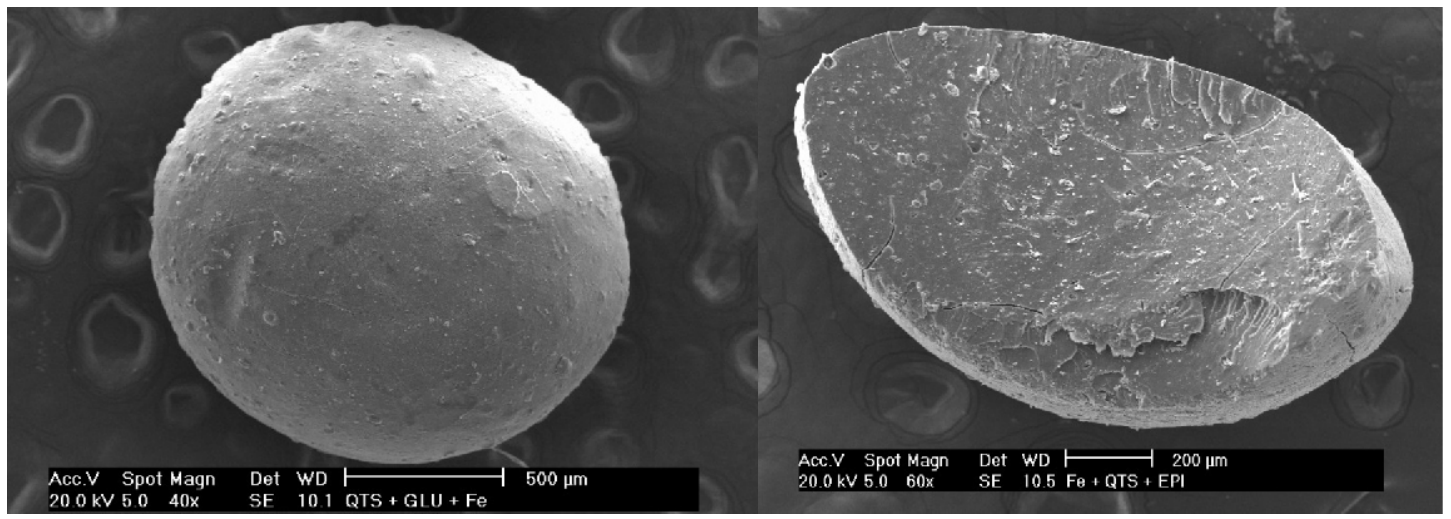

(a)

(b)

Figura 3. Micrografia eletrônica de varredura de microesferas de quitosana reticulada com glutaraldeído contendo ferro(III): (a) inteiras; (b) seccionadas

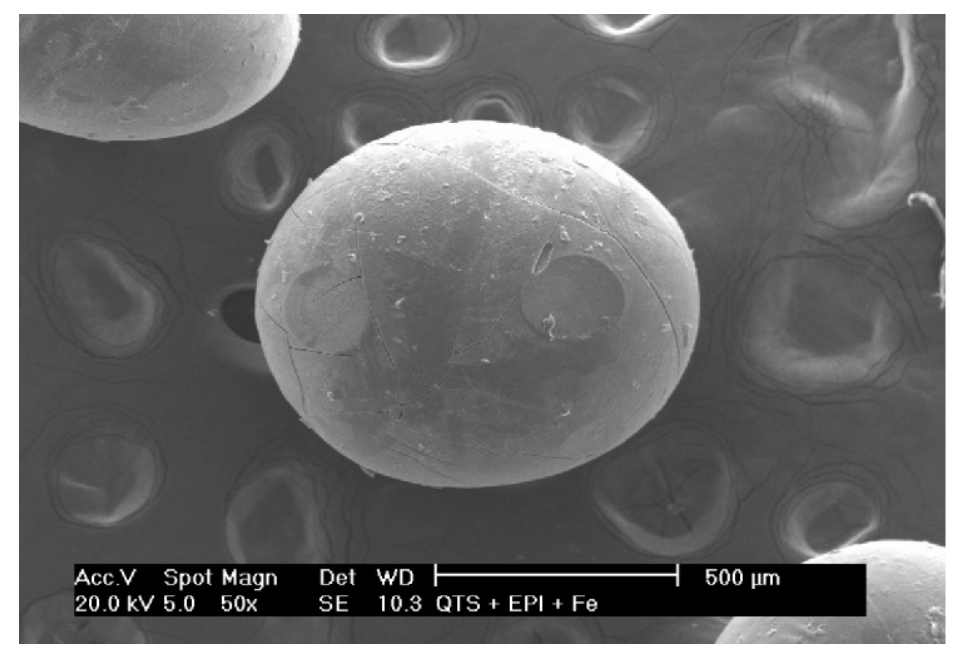

Figura 4. Micrografia eletrônica de varredura de microesferas de quitosana reticulada com epicloridrina contendo ferro (III).

Conforme parâmetros tais como: tamanho da agulha, tempo e velocidade de gotejamento.

As microesferas reticuladas com epicloridrina (1A) e glutaraldeído (2A) permaneceram em soluções tampão similares ao TGI $(\mathrm{pH} 1,2,6,8$ e 9,0) por 60 minutos a $37^{\circ} \mathrm{C}$ e foram rapidamente secas e pesadas para a determinação do grau de intumescimento. Os graus do intumescimento das microesferas reticuladas, $1 \mathrm{~A}$ e $2 \mathrm{~A}$, estão representados nas Figuras 5 e 6 , respectivamente.

Podemos observar que há um maior intumescimento em pH 1,2 das 
microesferas reticuladas com epicloridrina $(1 \mathrm{~A})$ devido a sua preferência por ligação em grupos hidroxila, deixando os grupos amino livres para protonação, sendo seguido do pH 6,8 e 9,0, o que confirma que a estrutura de reticulação é quimicamente estável.

Para as microesferas reticuladas com glutaraldeído (2A), verificamos um comportamento diferente. Ocorre um aumento gradativo do grau de intumescimento em pH 1,2 enquanto que para os demais valores de $\mathrm{pH}$ o intumescimento é constante. Isto, provavelmente, é devido a hidrólises parciais das ligações imino das bases de Schiff resultando em grupos amino livres novamente. Os mecanismos de hidrólises da base de Schiff em meios ácidos ou básicos são conhecidos. Gráficos que relacionam $\mathrm{pH}$ e velocidade de hidrólise mostram uma menor velocidade para $\mathrm{pH}>8,9$ e mais rápida e forte para $\mathrm{pH}<3,5$. (GONÇALVES et al., 2005)

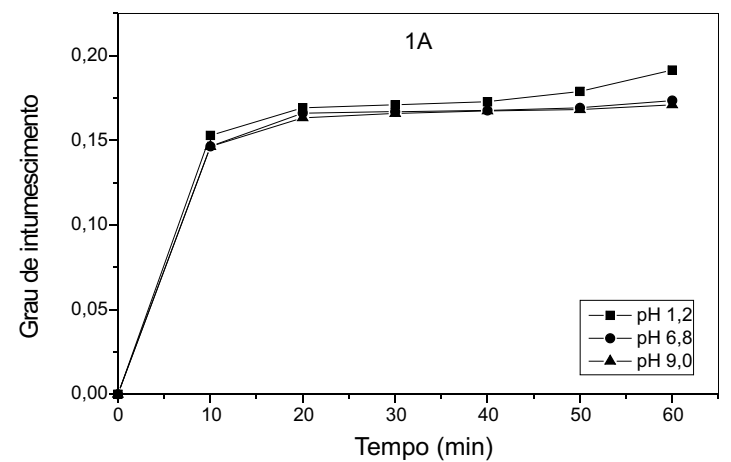

Figura 5. Grau de intumescimento de amostras 1A

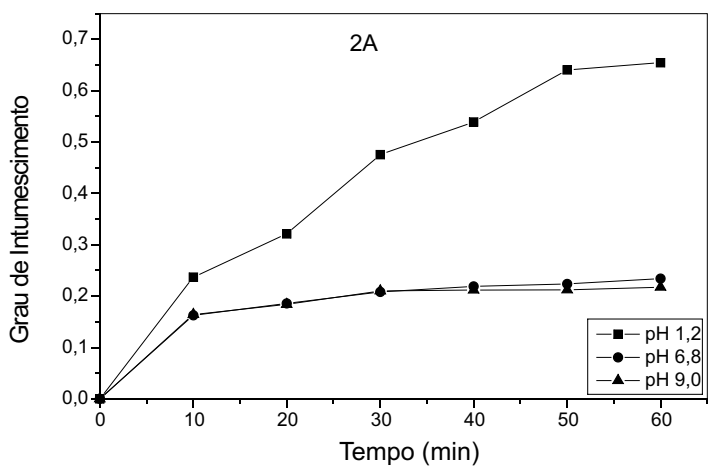

Figura 6. Grau de intumescimento de amostras 2A

As microesferas reticuladas ( $1 \mathrm{~A}$ e $2 \mathrm{~A})$ foram colocadas em contato por 24 horas em solução saturada de sulfato ferroso para o processo de impregnação. As concentrações de ferro nas microesferas foram determinadas após abertura das amostras. A complexação com 1,10-fenantrolina e leitura espectrofotométrica em UVvis a $510 \mathrm{~nm}$. Os resultados de impregnação foram de $25,6 \mathrm{mg} / \mathrm{g}$ seca para $1 \mathrm{~A}$ e 31,3 $\mathrm{mg} / \mathrm{g}$ seca para $2 \mathrm{~A}$.

A complexação de grupos amida ao ferro (III) pode ser ilustrada por espectroscopia infravermelho. Os espectros das microesferas de quitosana reticuladaferro(III) mostraram que a complexação não induziu a grandes mudanças no espectro infravermelho da quitosana reticulada. Entretanto, o espectro das microesferas QTSferro(III) mostram bandas de absorção em 1592 e $1588 \mathrm{~cm}^{-1}$ para as microesferas $1 \mathrm{Ae}$ $2 \mathrm{~A}$, respectivamente. Em contraste, o espectro da quitosana reticulada mostrou uma banda de carbonila de amida em $1650 \mathrm{~cm}^{-1}$. Assim, pode-se concluir que a banda de carbonila da amida foi deslocada para menor frequência sob complexação, confirmando que este deslocamento indica que o grupo amida está coordenado ao íon férrico (MARLIN, D.S.\& MASCHARAK, 2000).

A inclusão de novos grupos funcionais na quitosana pode afetar a estabilidade térmica. Atualmente, muitos estudos têm mostrado conclusões dependentes da natureza do grupo inserido. Por exemplo, no caso de derivados mercaptanas é visto que essas modificações químicas aumentam ligeiramente a estabilidade térmica, enquanto as bases de Schiff diminuem. Segundo Screenivasan (SCREENIVASAN, 1996) metais incorporados em polímeros, o comportamento térmico depende da 
natureza do metal. A adição de novas ligações através dos íons metálicos levaria ao aumento da estabilidade térmica, em compensação alterações na estrutura do polímero levaria a diminuição da estabilidade, sendo forças antagonistas com predomínio de uma ou outra.

As análises termogravimétricas da quitosana e dos complexos QTS Fe (III) das microesferas reticuladas $1 \mathrm{~A}$ e $2 \mathrm{~A}$ mostraram que a quitosana começa a perder massa de água de hidratação em $68^{\circ} \mathrm{C}(3,9 \%)$ e apresenta um pico de decomposição em 340C, este pico corresponde ao estágio da pirólise (despolimerização e decomposição das unidades acetiladas e desacetiladas do polímero) e resulta na perda de massa de $65 \%$. As microesferas reticuladas com epicloridrina $(1 \mathrm{~A})$ apresentam 3 picos: o primeiro corresponde a perda de massa por desidratação em $68^{\circ} \mathrm{C}$ e outros dois picos em $270^{\circ} \mathrm{C}$ e $336^{\circ} \mathrm{C}$ correspondem a decomposição das ligações cruzadas do polímero e das unidades de glucosamina, respectivamente. Para as microesferas reticuladas com glutaraldeído (2A) os 3 picos também são observados em $78^{\circ} \mathrm{C}$ referente a perda de água em, $289^{\circ} \mathrm{C}$ e $340^{\circ} \mathrm{C}$ com a mesma atribuição de decomposição.

Os espectros Mössbauer registrados a $298 \mathrm{~K}$ das amostras $1 \mathrm{~A}$ e $2 \mathrm{~A}$ são apresentados nas Figuras 7 e 8 (valores dos parâmetros hiperfinos desses espectros na Tabela 1).
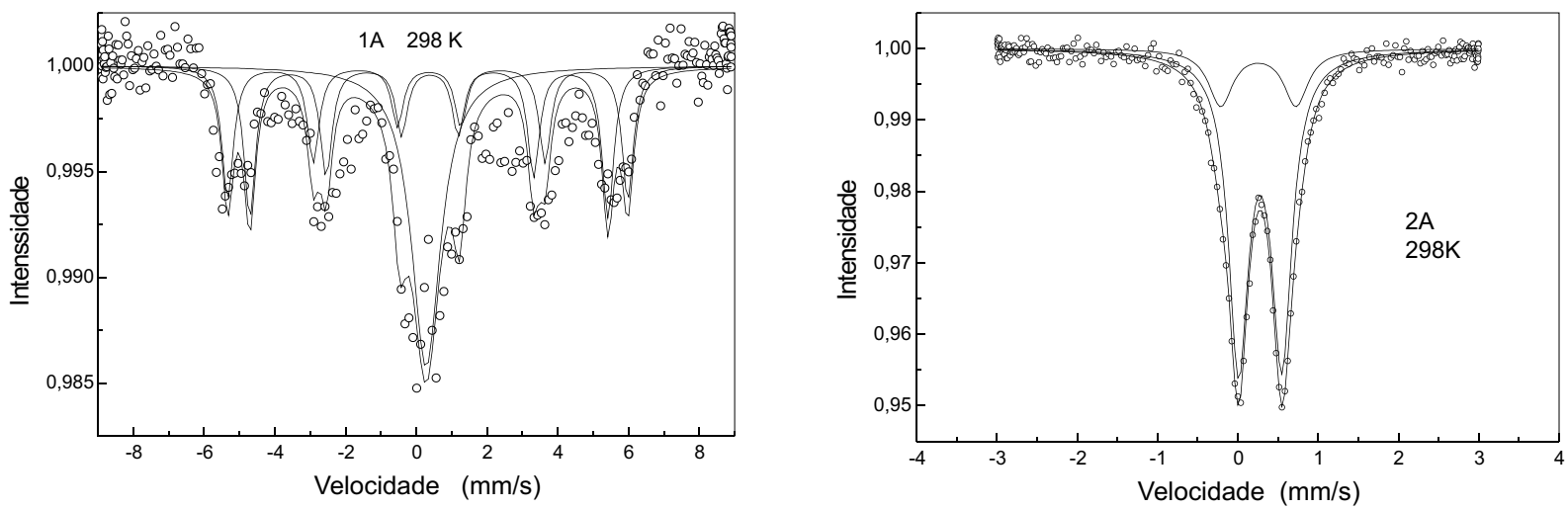

Figura 7. Espectro Mössbauer de amostras 2A Figura 8 Espectro Mössbauer de amostras $1 \mathrm{~A}$

Tabela 1 Parâmetros Mössbauer de Fe obtidos a $298 \mathrm{~K}$ para amostras $1 \mathrm{~A}$ e $2 \mathrm{~A}$. $\delta=$ deslocamento isomérico relativo ao $\alpha \mathrm{Fe} ; \Delta \mathrm{Eq}=$ desdobramento quadrupolar, $\mathrm{AR}=$ área relativa subespectral $\Gamma=$ largura de linha a meia altura

\begin{tabular}{|c|c|c|c|c|}
\hline Amostra & $\delta / \mathrm{mm} \mathrm{s}^{-1}$ & $\Delta \mathrm{Eq} / \mathrm{mm} \mathrm{s}^{-1}$ & $\mathrm{AR} / \%$ & $\Gamma / \mathrm{mm} \mathrm{s}^{-1}$ \\
\hline $1 \mathrm{~A}$ & 0,34 & 0,30 & 38 & 0,60 \\
\hline $2 \mathrm{~A}$ & 0,34 & 0,54 & 82 & 0,30 \\
\hline
\end{tabular}

O espectro Mössbauer para as microesferas QTS-Fe (III) reticuladas com epicloridrina (1A), apresentou deslocamento isomérico, $\delta=0,34 \mathrm{~mm} / \mathrm{s}$ e desdobramento quadrupolar, $\Delta \mathrm{Eq}=0,30 \mathrm{~mm} / \mathrm{s}$ o que evidencia a presença de Ferro (III) de configuração alto spin. Os íons ferro aparentemente não estão complexados ao polímero e sim dispersos na forma de núcleos de óxido de ferro (III). Estes núcleos são constituídos basicamente por magnetita $\left(\mathrm{Fe}_{3} \mathrm{O}_{4}\right)$ superparamagnética com uma distribuição larga de 
diâmetro dos grãos podendo ir de 5 a $20 \mathrm{~nm}$. Os grupos doadores dos polissacarídeos atuam como sítios de nucleação para os íons metálicos, os quais os ligam através da formação de ligações de hidrogênio e uma variedade de nanoestruturas é formada in situ, com tamanho e formas que dependem do tipo do polímero e propriedades da solução (pH, temperatura, etc.) (SIPOS et al., 2003; BHATIA \& RAVI, 2003) As demais bandas do espectro apresentam dubletos mal resolvidos de Fe (III) o que pode indicar que a formação da "super estrutura" de magnetita ainda não se completou.

O espectro Mössbauer para as microesferas QTS-Fe (III) reticuladas com glutaraldeído $(2 \mathrm{~A})$, mostrou deslocamento isomérico, $\delta=0,34 \mathrm{~mm} / \mathrm{s}$ típico de complexo Fe (III) alto spin com $\sigma$ doadores. Entretanto, o dubleto com desdobramento quadrupolar, $\Delta \mathrm{Eq}=0,54 \mathrm{~mm} / \mathrm{s}$ indica a existência de distorção na estrutura do complexo octaédrico produzido pela presença de ligantes de diferente natureza. Este espectro sugere ao menos quatro ligantes e no máximo 6 coordenações para o complexo com ligantes $\mathrm{N} / \mathrm{O}$. Entretanto, o deslocamento isomérico não prova realmente que o $\mathrm{N}$ amínico está ligado ao metal. O fato de o espectro apresentar linhas de largura fina, $0,30 \mathrm{~mm} / \mathrm{s}$ indica um ambiente de coordenação mais simétrico e sugere pequenas variações locais, com menor distorção da estrutura. Ainda pode-se sugerir a presença de núcleos de magnetita em menor quantidade.

Os valores de deslocamento isomérico, $\delta$, observado para ambos os espectros são coerentes com os detectados para compostos de Fe (III) na configuração alto spin (KNIGHT; BOWEN; BEREMAN, 1996; GYURESIK \& NAGY, 2000; BHATIA \& RAVI, 2000) sendo que esta atribuição está de acordo com as medidas magnéticas de Nieto e col. (NIETO; PENICHE-COVAS; DELBOSQUE, 1992)

Por fim, muitos trabalhos envolvendo o estudo da interação da quitosana com Fe (III) foram desenvolvidos e comparados. Com o processo de reticulação da quitosana realizado neste trabalho, microambientes alternativos foram criados para a formação de estruturas diversas.

O perfil de liberação de ferro (III) das microesferas 1A e 2A está representado na Figura 9. Quando analisado o perfil de liberação para fármacos contendo ferro, devese levar em consideração a dependência da solubilidade em função do pH. O ferro (III) inicia a sua precipitação em pH próximo de 3. Portanto os estudos de liberação foram realizados em pH 1,2 simulando o suco gástrico e , onde ocorre maior absorção do metal, o que justifica o perfil realizado apenas neste $\mathrm{pH}$.

Após 2 horas em pH 1,2, ocorre a liberação de cerca de $20 \%$ e $36 \%$ para as microesferas $1 \mathrm{~A}$ e $2 \mathrm{~A}$, respectivamente. O grau de reticulação juntamente com o grau de intumescimento de cada matriz polimérica é um fator determinante para o processo de liberação.

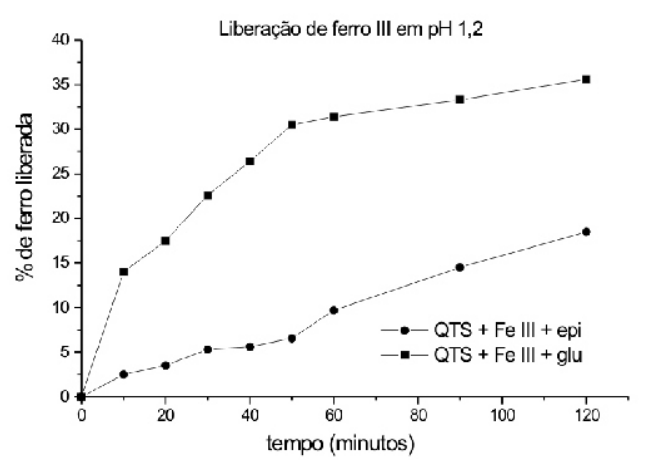

Figura 9. Liberação in vitro de ferro (III) das microesferas $1 \mathrm{~A}$ e $2 \mathrm{~A}$ 


\section{Conclusão}

Microesferas de quitosana reticuladas com epicloridrina ou glutaraldeído apresentam diferentes comportamentos referentes ao intumescimento, grau de reticulação e quantidade e a forma de ferro impregnada. Os espectros de Mössbauer mostraram que nas microesferas reticuladas com epicloridrina os íons ferro não estariam complexados ao polímero e sim dispersos na forma de núcleos de magnetita, enquanto para as microesferas reticuladas com glutaraldeído mostra um comportamento de complexo de $\mathrm{Fe}$ (III) alto spin com doadores $\sigma$. Com relação à liberação do ferro (III) em pH 1,2 as microesferas reticuladas com glutaraldeído apresentaram maior eficiência do que as reticuladas com epicloridrina.

\section{Referências}

BERGER, J.; REIST, M.; FELT, O.; PEPPAS, N.A.; GURNY, R. Structure and interactions in covalently and ionically crosslinked chitosan hydrogels for biomedical applications. European Journal Pharm. Biopharmac., v.57, p.19-34, 2004.

BHATIA, S.C.; RAVI, N. A magnetic study of na Fe- chitosan complex and its relevance to other biomolecules. Biomacromolecules, v.1, p.413-417, 2000.

BHATIA, S.C.; RAVI, N. A Mössbauer sutdy of the interaction of chitosan and Dglucosamine with iron and its relevance to other metalloenzymes. Biomacromolecules, v.4, p.723-727, 2003.

DENKBAŞ, E.B.; KILIÇAY, E.; BIRLIKSEVEN,C.;ÖZTÜRK,E. Magnetic chitosan microspheres: preparation and characterization. Reactive\& Functional Polymers, v.50, p.225-232,2002.

GAMBLIN, B.E.; STEVENS, J.G.; WILSON, K.L. Structural investigations of chitin and chitosan complexed with iron or tin. Hyperfine Interactions, v. 112, p. 117-122, 1998.

GEETHA, K.; RAGHAVAN, M.S.S.; KULSHRESHTHA, S.K.; SASIKALA,R.; RAO, C.P. Transition-metal saccharide chemistry: synthesis, spectroscopy, electrochemistry and magnetic susceptibility studies of iron (III) complexes of mono-and disaccharides. Carbohydrate Research, v.271, p.163-175, 1995.

GONÇALVES, V.L; LARANJEIRA, M.C.M; FÁVERE, V.; PEDROSA, R.C. Effect of crosslinking agents on chitosan microspheres in controlled release of diclofenac sodium. Polímeros:Ciência e tecnologia, v. 15, n.1, p.6-12, 2005.

GYURESIK, B.; NAGY, L. carbohydrates as ligands: coordinations equilibra and structure of the metal complexes. Coordination Chemistry reviews, v.203, p. 81-149, 2000.

HEJAZI, R.; AMIJI, M. Chitosan-based gastrointestinal delivery systems. J.Controlled Release, v. 89, p.151-165, 2003.

JUSTI, K. C.; Laranjeira, M.C. M.; Neves, A; Mangrich, A. S.; FÁVere, V. T. Chitosan functionalized with 2[-bis-(pyridylmethyl) aminomethyl]4-methyl-6-formyl-phenol: equilibrium and kinetics of copper (II) adsorption. Polymer, v. 45, p. 6285-6290, 2004.

KNIGHT, B.; BOWEN, L.H.; BEREMAN, R.D. Mössbauer studies of some polysaccharide-iron complexes used as hematinics. J. Inorganic Biochemistry, v. 64, p.225-229, 1996. 
MARLIN, D.S.; MASCHARAK, P.K.,.Coordination of carboxamido nitrogen to tervalent iron: insight into a new chapter of iron chemistry. Chem. Soc. Rev., v. 29, p. 6974, 2000. NIETO, J.M.; PENICHE-COVAS, C.; DEL BOSQUE, J. Preparation and characterization of a chitosan-Fe(III) complex. Carbohydrate Polymers, v.18, p.221224, 1992.

OKUYAMA, K.; NOGUCHI,K.; KANEMARI,M.; EGAWA, T.; OSAWA, K.; OGAWA, K. Structural diversity of chitosan and its complexes. Carbohydrate Polymers, v. 41, p.237-247,2000.

SIPOS, P.; BERKESI, O.; TOMBÁCZ,E.; ST.PIERRE, T.G.; WEBB, J. Formation of spherical iron (III) oxyhydroxide nanoparticles sterically stabilized by chitosan in aqueous solution. J. Inorganic Biochemistry, v. 95, p.55-63, 2003.

SIPOS, P.; ST.PIERRE, T.G.; TOMBÁCZ,E.; WEBB, J. Rod-like iron (III) oxyhydroxide particles in iron (III)-polysaccharide solutions. J. Inorganic Biochemistry, v. 58, p.129138, 1995.

SREENIVASAN, K. Thermal stability studies of some chitosan-metal ion complexes using differential scanning calorimetry. Polymer Degradation and Stability, v.52, p.85$87,1996$. 